\title{
Optimization of thrust propeller design for an ROV (Remotely Operated Vehicle) consideration by Genetic Algorithms
}

\author{
Aldias Bahatmaka ${ }^{1,3^{*}}$, Dong-Joon $\mathrm{Kim}^{2}$, Deddy Chrismianto ${ }^{3}$, Nguyen $\mathrm{Hai}^{1}$, and Aditya Rio \\ Prabowo ${ }^{1}$ \\ ${ }^{1}$ Pukyong National University, Interdisciplinary Program of Marine Design Convergence, 48513 \\ Busan, South Korea \\ ${ }^{2}$ Pukyong National University, Department of Naval Architecture and Marine Systems Engineering, \\ 48513 Busan, South Korea \\ ${ }^{3}$ Diponegoro University, Department of Naval Architecture, 50269 Semarang, Indonesia
}

\begin{abstract}
Remotely Operated Vehicle (ROV) is one of the technology that can facilitate for observing and exploring the underwater condition (sea). The design and manufacturing process of underwater robots needs many support and increase the performance of the underwater robot to do some missions. Thruster is one of main component which has function as an actuator during the operation. In the present study, propeller design the most important for solving the problem of an ROV. For the optimization of thrust, Genetic Algorithms (GA) can powerfully search for parameters in large multidimensional design space. Thus, the principle can be applied for determining the initial dimension of the propeller for producing optimum thrust of ROV. GA was successfully shown able to obtain an optimal set of parameters leading to propeller characteristics and best performances.
\end{abstract}

\section{Nomenclature}

$A_{E} \quad$ propeller expanded area

$A_{0}$ propeller disk area

$C_{T n}$ regression coefficient of thrust coefficient

$C_{Q n}$ regression coefficient of torque coefficient

$D$ diameter propeller

$J$ advance coefficient

$K_{T} \quad$ thrust coefficient

$K_{Q}$ torque coefficient

$n \quad$ propeller rotating speed

$P \quad$ propeller blade pitch

$P / D$ pitch diameter ratio

$Q \quad$ torque $(\mathrm{Nm})$
$S_{n} \quad$ exponent of $J$

$T$ thrust

$t_{n} \quad$ exponent of $P / D$

$U_{n} \quad$ exponent of $A_{E} / A_{0}$

$V_{n} \quad$ exponent of $Z$

$Z$ number of blades

$\rho \quad$ density of water

\footnotetext{
*Corresponding author: aldias@pukyong.ac.kr
} 


\section{Introduction}

Remotely Operated Vehicle (ROV) is an instrument formed mini-sized submission vehicle. ROV is usually to explore underwater object, such as underwater photography, military operation and underwater pipeline repairing. ROV is used for activities in humanunreached area like an underwater small cave. ROV is designed to have abilities to rescue operation and repairing of object from the surface [1].

Underwater robot design and manufacturing absolutely requires many supporting components to improve the underwater robot operation to perform a variety of underwater missions. Thruster is one of main components as locomotor of underwater robot to maneuver horizontally when it moves forward and backward and vertically to moves up and down [2].

The first proposal to use screw propeller appears to have been made in England by Hooke in 1680 [3]. The genetic algorithms are one of method that has tool for optimization for many difficult optimization problems with multi objectives. GA methods were shown to be able to replace the traditional computation method and design charts. In this case for determining the initial propeller that optimum for ROV thruster is difficult. For selecting the initial propeller, used optim-tools in Genetic Algorithms. However, the traditional design charts method and previous GA methods were limited in considering or maximum of hydrodynamic aspect, such as efficiency, thrust coefficient, etc. hence, the goals of present research to determine the optimum value of thrust for ROV by 3 parameters, pitch diameter ratio, expanded blade area ratio, and rotational speed of propeller. Applying GA methods to propeller design with consideration of thrust for reaching the best performance of propeller.

\section{Propeller design}

The preliminary propeller design problem is described in detail in the principles of Naval Architecture. Here is the basic design or initial design of propeller with the dimension for dependent variables as shown in Table 1. For independent variables as presented in Table 2.

Table 1. Dependent variables.

\begin{tabular}{|c|c|}
\hline Items & Unit \\
\hline Diameter & $130.00 \mathrm{~mm}$ \\
\hline $\begin{array}{c}\text { Number of } \\
\text { blades }(\mathrm{z})\end{array}$ & 5 blades \\
\hline Material & $\begin{array}{c}\text { Mn.Bronze } \\
(2)\end{array}$ \\
\hline $\begin{array}{c}\text { Rake } \\
\text { ofangle }\end{array}$ & 15.00 degree \\
\hline $\begin{array}{c}\text { Density of } \\
\text { water }\end{array}$ & $1.025 \mathrm{~kg} / \mathrm{m}^{3}$ \\
\hline
\end{tabular}


Table 2. Independent variables.

\begin{tabular}{|l|l|l|l|}
\hline & I & II & III \\
\hline $\mathrm{P} / \mathrm{D}$ & 0.60 & 0.65 & 0.70 \\
\hline $\mathrm{AE} / \mathrm{A} 0$ & 0.75 & 0.80 & 0.85 \\
\hline Rotational speed $(n)$ & $5 \mathrm{rps}$ & $10 \mathrm{rps}$ & $15 \mathrm{rps}$ \\
\hline
\end{tabular}

\subsection{Parameters of optimization}

Selecting from a propeller series is a simple method to design a propeller. Among the series propeller is one of the most often used and studied [4]. And selection of the table was improved later.

\section{Genetic algorithms (GA)}

The basic theory has been described [5]. Genetic algorithms are search algorithms based on the mechanics of natural selection and natural genetics. They combine survival of the fittest among string structure with structured yet randomized information exchange to inform a structure algorithms with some of the innovative flair of human search.

Based on the theory, the research was conducted with set of parameters dependent and independent variables. For the first steps were identifying variables and functions the propeller of ROV. There are three variables that we could change randomly as like as P/D 9pitch ratio), AE/A0 (expanded blade area ratio), and $\mathrm{n}$ (rotational speed). From this process, we could get the value of $\mathrm{K}_{\mathrm{T}}$ and $\mathrm{K}_{\mathrm{Q}}$. Thus, the thrust $(\mathrm{T})$ amd torque $(\mathrm{Q})$ can be expressed in Eq.1 and 2.

\section{Function:}

$$
\begin{gathered}
T=K_{T}\left(\rho n^{2} D^{4}\right) \\
Q=K_{Q}\left(\rho n^{2} D^{5}\right)
\end{gathered}
$$

The fitness function we used as the functions of the blade number, blade area ratio, pitch ratio and advanced coefficient can be described in the Eq.6 and 7.

\section{Fitness function:}

$$
K_{T}=\sum_{n=1}^{39} C_{T n} J^{S n}\left(\frac{P}{D}\right)^{t n}\left(\frac{A_{E}}{A_{0}}\right)^{U n} Z^{v n}
$$




$$
K_{Q}=\sum_{n=1}^{47} C_{Q n} J^{S n}\left(\frac{P}{D}\right)^{t n}\left(\frac{A_{E}}{A_{0}}\right)^{U n} Z^{v n}
$$

Where $\mathrm{C}_{\mathrm{Tn}}$ and $\mathrm{C}_{\mathrm{Qn}}$ are the regression coefficients of the thrust and torque coefficients respectively, $S_{n}, t_{n}, U_{n}$ and $v_{n}$ are exponents of $J, P / D, A E / A 0$, and $Z$ respectively.

The constraint function can be created in Eq.5 and 6.

\section{Constraints:}

$$
0.60 \leq \frac{P}{D} \leq 0.70
$$

$$
5 \leq n \leq 15
$$

\section{Optimization procedures}

For the process of optimization shown in Fig.1. The optimization tools which is supported by MATLAB program for the solution of genetic algorithms method. This study, GA apply to know how is the optimum thrust for the initial propeller using the parameters and setup for GA is shown in Table 3.

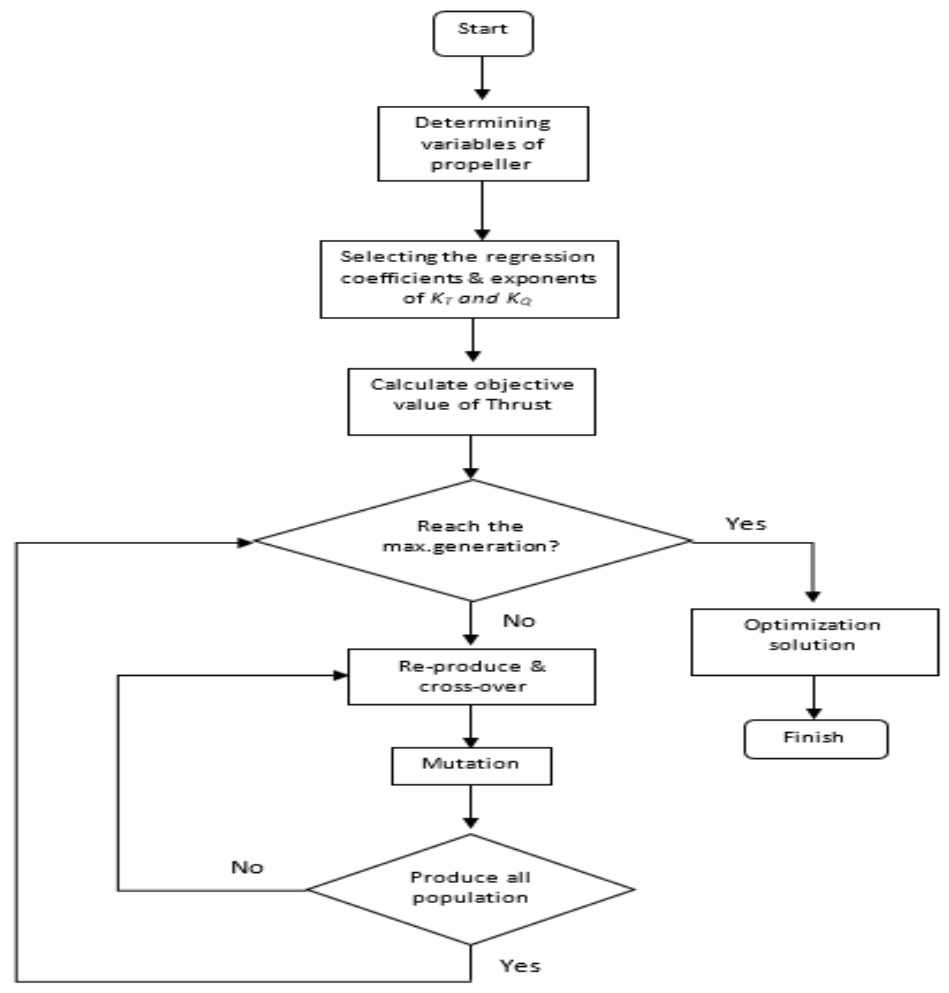

Fig. 1. Flowchart of genetic algorithms. 
Table 3. Setting up the GA parameters.

\begin{tabular}{|c|c|}
\hline \multicolumn{2}{|c|}{ Population size $=\mathbf{2 0}$} \\
\hline $\begin{array}{c}\text { Number of } \\
\text { generations }\end{array}$ & 80 \\
\hline Selection & $\begin{array}{c}\text { Stochastic } \\
\text { uniform }\end{array}$ \\
\hline $\begin{array}{c}\text { Crossover } \\
\text { rate }\end{array}$ & 0.8 \\
\hline $\begin{array}{c}\text { Crossover } \\
\text { function }\end{array}$ & Scattered \\
\hline $\begin{array}{c}\text { Mutation } \\
\text { rate }\end{array}$ & 0.2 \\
\hline
\end{tabular}

\section{Results and discussion}

\subsection{Optimization Output}

The output of optimum thrust can be shown in Table 4. And results can be exported by genetic algorithms as shown in Fig. 2.

Table 4. Output.

\begin{tabular}{|c|c|c|c|}
\hline Iteration & P/D & AE/A0 & n (rps) \\
\hline 51 & 0.60 & 0.79 & 5.00 \\
\hline
\end{tabular}




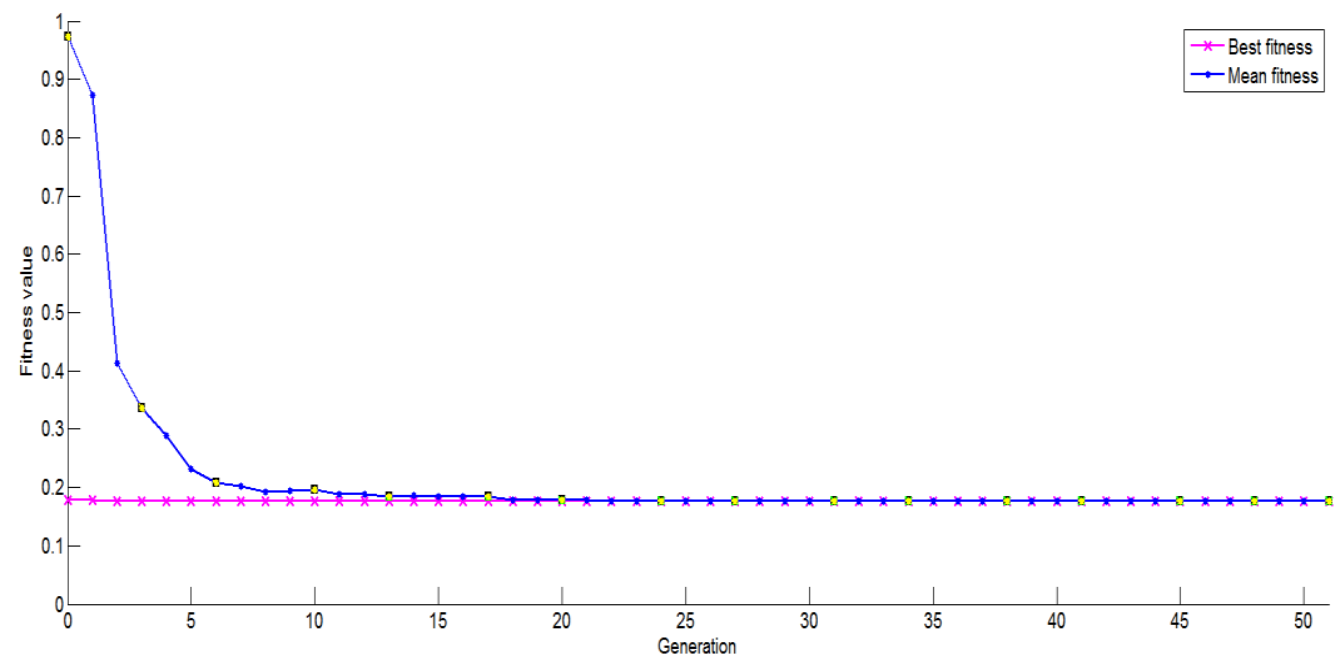

Fig. 2. Fitness value through the generations

At the 51 iterations using GA, the thrust will be optimum when the value of $\mathrm{P} / \mathrm{D}$ (pitch ratio) is $0.60, \mathrm{AE} / \mathrm{A} 0$ (expanded area ratio) is 0.79 and the value of rotational speed is $5 \mathrm{rps}$.

\subsection{Final Results}

The difference of computational result can be seen in Table 5.

Table 5. Comparison the final results.

\begin{tabular}{|c|c|c|c|}
\hline Results & Original & New & Differences \\
\hline Force $(\mathrm{N})$ & 2.530 & 3.224 & $+27.43 \%$ \\
\hline
\end{tabular}

Based on the results, the thrust is increasing $27.43 \%$ from $2.530 \mathrm{~N}$ to $3.224 \mathrm{~N}$. it means the optimization of the thrust for the propeller of ROV is reached and satisfied. And results of new design as shown in Fig.3 for the streamline simulation and Fig.4 for the pressure contour. 

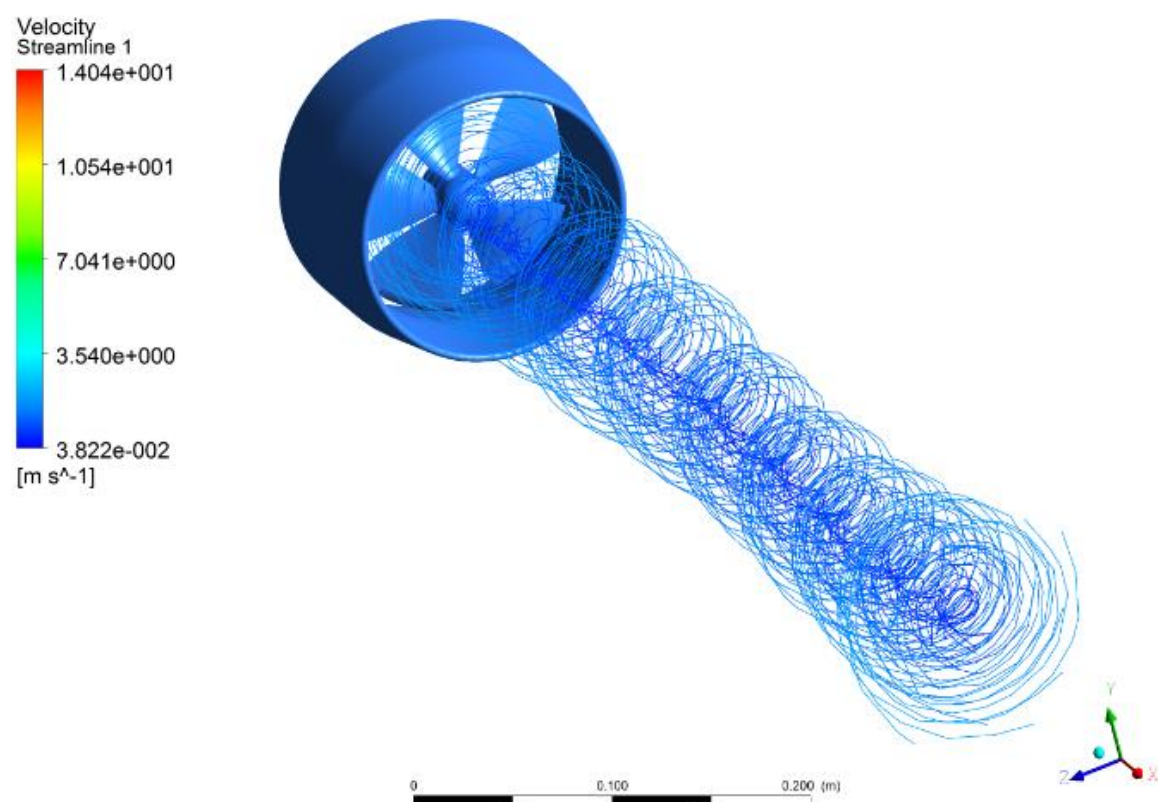

Fig. 3. Streamline simulation
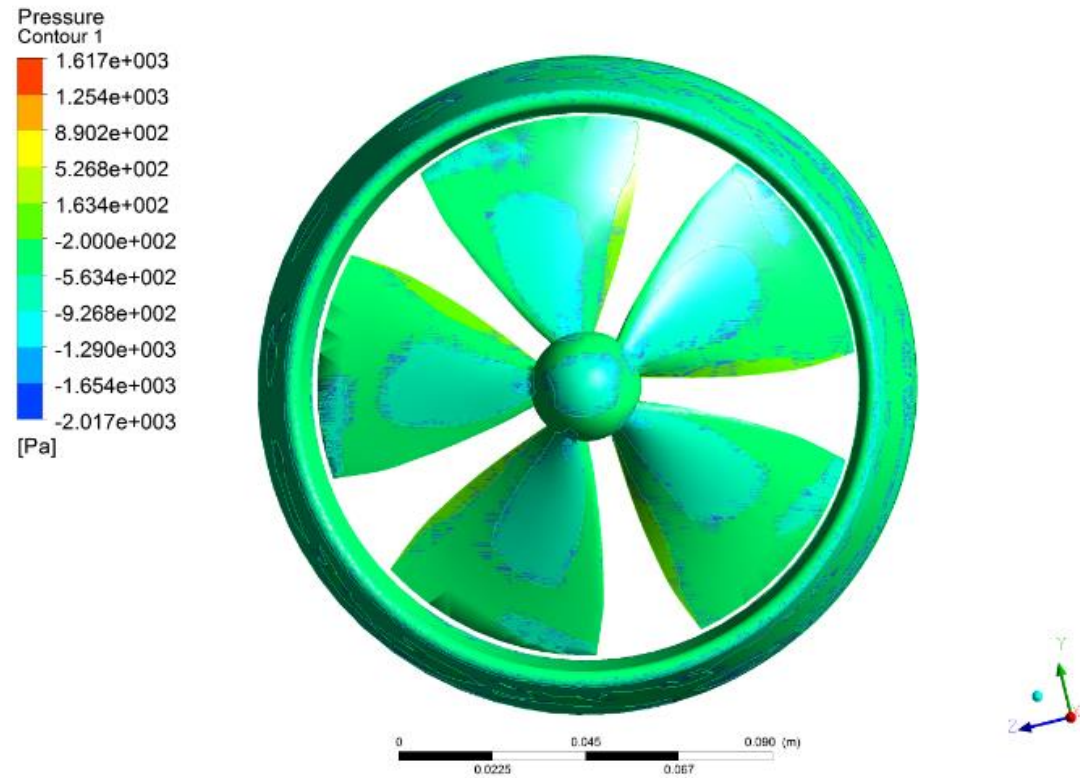

Fig. 4. Pressure contour 


\section{Conclusion}

In this paper, study on development of the propulsion device for an ROV (Remotely Operated Vehicle). The GA is applied for optimization design of the initial propeller dimension and the results show that it is good for kind of the problems. The optimization of propeller for an ROV has been proposed and provides the solution to ROV thruster and GA optimization can be employed due to propeller performances.

\section{Acknowledgement}

This work successfully published with support from BK21 plus MADEC Human Research Development Group, Pukyong National University, South Korea. The corresponding author would like to thanks to his professor and the people who help and support for this research.

\section{References}

1. R. D. Roberto, Sr. L. Wernli, Robert, The ROV manual, Burlington, MA 01803, UK, (2007)

2. A. Sharkh, S., Harris, et al. Design considerations for electric drives for the thrusters of unmanned underwater vehicles $\left(6^{\text {th }}\right.$ ECEA, Sevilla, pp.799-801, 1995)

3. J. D. V. Manen, P. Van Ossanen, PNA, 2 (1988)

4. G.Kuiper, New developments around sheet and tip vortex cavitation on ships propellers (Caltech, 2001)

5. D.E.Goldberg, Genetic algorithms in search, optimization, and machine learning (Addion Wesley, p.102, 1989) 